\title{
LEVIATÃ PARA JOVENS? O CONCEITO DE ESTADO NOS LIVROS DIDÁTICOS DE SOCIOLOGIA
}

\author{
LEVIATHAN FOR YOUTH? THE CONCEPT OF STATE \\ IN COURSEBOOKS OF SOCIOLOGY
}

André Rocha Santos 1

Alessa Coelho Lauriano ${ }^{2}$

Recebido: 02 mar. 2019

Aceite: 05 jun. 2019

DOI https://doi.org/10.29327/2.1373.1-11

RESUMO: Análise dos conhecimentos de política na disciplina de sociologia no ensino médio e do tratamento dado à temática do Estado no âmbito dos documentos oficiais e dos livros didáticos disponibilizados pelo governo federal aos alunos da rede pública por meio do Programa Nacional do Livro Didático (PNLD) na sua edição 2018 (utilizados no triênio 2018-2019-2020). O objetivo é fazermos uma reflexão desse conteúdo tendo por base os principais Autores, Conceitos, Temas e Teorias utilizados. Por fim, iremos avaliar esse material analisando de forma crítica sua abordagem, seus limites e desafios.

PALAVRAS-CHAVE: Estado; Livro didático; Sociologia.

ABSTRACT: Analysis of the knowledge of politics in the discipline of sociology in high school and of the treatment given to the State theme in the scope of the official documents and of the didactic books made available by the federal government to the students of the public network through the National Program of Didactic Book (PNLD) in the its 2018 edition (used in the triennium 2018-2019-2020). The objective is to make a reflection of this content based on the main Authors, Concepts, Themes and Theories used. Finally, we will evaluate this material by critically analyzing its approach, its limits and challenges.

KEYWORDS: State; Coursebook; Sociology; PNLD.

\footnotetext{
1 Doutor em Sociologia pela Universidade Estadual Paulista (Unesp). Docente no Instituto Federal de São Paulo (IFSP). E-mail: andrerochasantos@gmail.com ORCID iD https://orcid.org/0000-0001-8085-5305

2 Graduanda em Ciências Sociais pela Universidade Federal do Paraná (UFPR). E-mail: alessa_rgt@hotmail.com ORCID iD https://orcid.org/0000-0001-7068-4290
} 


\section{INTRODUÇÃO}

“O jovem brasileiro não se interessa por política". "Ele é um alienado!” Frequentemente ouvimos frases como essa em nossa sociedade, ditas pelo senso comum na família, na escola, nos meios de comunicação. Mas, será que é isso mesmo? Ou há, de forma proposital, um estímulo ao desinteresse e à confusão de conceitos e valores com o intuito de fazer com que o jovem não tenha consciência das questões sociais, políticas, econômicas e culturais que o cercam e assim o debate possa ser monopolizado por certos indivíduos, grupos e classes sociais?

Este tema - os conhecimentos de política na educação básica - tem atraído especial atenção nos últimos anos, em particular os temas, conceitos, teorias e autores presentes no currículo do ensino médio em confronto com os novos movimentos ultraconservadores que buscam desqualificar e anular o debate político trabalhado com os jovens brasileiros na escola pública num clima de perseguição e patrulha ideológica acusando determinados professores de "ideologização do ensino" e de "doutrinação marxista" (AÇÃO EDUCATIVA, 2016).

Em paralelo a isso, no entanto, é evidente o aumento da curiosidade dos jovens pela política. Estimulados pela internet e pelas redes sociais, não faltaram eventos importantes no contexto nacional para se discutir o assunto. Iniciado pelas manifestações de junho de 2013, passando pelas eleições presidenciais de 2014 e pela ocupação de mais de 190 escolas pelos estudantes contra o plano de "reorganização" da rede estadual paulista em 2015, os jovens desempenharam papel decisivo em todas essas discussões. Da mesma forma, nos anos seguintes, não faltaram motivos para os jovens cidadãos brasileiros se manifestarem e darem a sua opinião: nas manifestações contra ou a favor o impedimento da presidente Dilma Rousseff, nos protestos contra o presidente da Câmara dos Deputados Eduardo Cunha, em oposição ao governo Michel Temer e sua agenda política de cortes no orçamento para Educação, Saúde e Previdência e nas eleições presidenciais de 2018, na qual, inclusive, o candidato eleito de extrema-direita - Jair Bolsonaro - é defensor de movimentos que defendem a censura e a intimidação aos professores em sala de aula (REVISTA VEJA, 2019). 
Em um momento conturbado como o que vivemos atualmente, em que muito se fala sobre e de política, fica evidente como muitas pessoas simplesmente não sabem do que estão falando. Embaralhados pelo incessante disparo de informações vindas principalmente da internet, misturamse e confundem-se valores caros ao ideal Republicano e ao Estado Democrático em vídeos, artigos, opiniões e declarações muitas vezes antidemocráticas e carregadas de ódio, preconceito e autoritarismo (AÇÃO EDUCATIVA, 2016).

Nesse contexto, o estudo das ciências sociais no ensino médio, isto é, a sociologia, a antropologia e a ciência política - que por simplificação foram denominadas apenas como sociologia, mas que abarcam o saber escolar indispensável das três áreas - passa a atrair um sentido especial de esclarecimento e de se afastar a ignorância política.

Desse modo, cabe a pergunta: qual o papel dos conhecimentos de política na escola brasileira? Como esse conteúdo deve ser abordado no currículo escolar? Em que momento deve ser oferecido? Com quais conceitos, temas ou teorias?

$\mathrm{Na}$ escola, noções básicas da política como Cidadania, Democracia, República, Ditadura, Liberalismo, Socialismo, Social-Democracia, Neoliberalismo, Movimentos Sociais, Partidos Políticos e outros, são essenciais. A abordagem do que são esses temas e teorias deve servir ao aprendizado e à conscientização política. Da mesma maneira, conceitos fundamentais como poder, igualdade, liberdade, tolerância, ética, espaço público, ideologia, consenso, conflito, hegemonia e utopia necessitam servir ao esclarecimento e à compreensão do mundo que os cerca.

Nesse sentido, a inclusão da sociologia nos currículos do ensino médio brasileiro a partir da lei 11.684/2008 se constituiu em um verdadeiro marco na educação nacional e impôs novos desafios aos conhecimentos de ciências sociais que se pretendem adequados e necessários aos nossos alunos. A medida recompensou mais de cinquenta anos de discussões, lutas e debates de vários intelectuais, entidades, organizações de classe e movimentos sociais pela reintrodução definitiva da disciplina na grade curricular nacional, além do fato de que "desafiou o campo sociológico brasileiro a atravessar o verdadeiro abismo que o separa da realidade do ensino médio” (BRAGA, 2009, p.163).

Consequentemente, tiveram início nos anos seguintes a produção de materiais, livros didáticos, seminários, encontros e pesquisas acadêmicas discutindo quais conteúdos deveriam estar 
presentes, por meio de quais autores, utilizando quais abordagens e teorias, tanto sociológicas, antropológicas e políticas quanto educacionais. Órgãos de governo como o Ministério da Educação (MEC), as Secretarias Estaduais de Educação e instituições da sociedade civil como universidades e centros de pesquisa passaram a debater o que, como e por que essas questões deveriam ser ensinadas, assim como o desafio da transposição de um saber acadêmico para um saber escolar (MEUCCI, 2014).

Nossa intenção, portanto, é fazer uma análise do conceito de Estado nos documentos oficiais e nos cinco livros didáticos escolhidos na edição 2018 e que estão atualmente em sala de aula: Sociologia (ARAÚJO; BRIDI; MOTIM, 2016), Tempos modernos, tempos de sociologia (BOMENY et al., 2016), Sociologia hoje (MACHADO, AMORIM; BARROS, 2017), Sociologia para jovens do século XXI (OLIVEIRA; COSTA, 2016) e Sociologia em movimento (SILVA et al., 2016). O objetivo é avaliar o conceito de Estado nesse material em termos de conteúdos, analisando principalmente sua abordagem (conservadora, liberal, socialista), seus limites e desafios, buscando preencher a lacuna existente em investigações desse tipo.

\section{O CONCEITO DE ESTADO NOS DOCUMENTOS OFICIAIS}

De acordo com os Parâmetros Curriculares Nacionais (PCN), "o estudo das Ciências Sociais no Ensino Médio tem como objetivo mais geral introduzir o aluno nas principais questões conceituais e metodológicas das disciplinas de Sociologia, Antropologia e Política" (p. 317). Para tanto, as principais questões conceituais e metodológicas referentes aos conhecimentos de política sistematizados nos PCN e que devem ser trabalhadas com o aluno do ensino médio foram explicitados no documento da seguinte forma:

Ampliando-se o escopo de análise, o estudo do Estado deverá produzir uma síntese que contemple as diversas teorias sobre sua origem e finalidade. Determinadas formas históricas de Estado, o Absolutista, o Liberal, o Democrático, o Socialista, o Welfare-State (o do Bem-Estar) e o Neoliberal, poderão ser abordadas e comparadas, em suas características, com o Estado Brasileiro atual.

De tal modo, pretende-se discutir alguns pontos do conceito de Estado: a soberania, sua estrutura de funcionamento, os sistemas de poder, as formas de governo no mundo atual, as características dos diferentes regimes políticos. E, por 


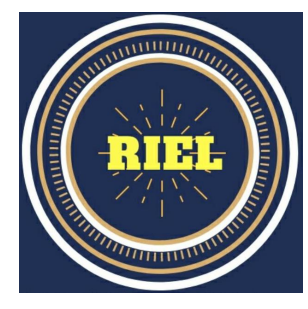

fim, algumas questões relevantes no contexto social brasileiro, tais como as relações entre o público e o privado e a dinâmica entre centralização e descentralização. Em termos históricos, cabe também realizar uma reflexão sobre a relação entre Estado e sociedade, identificando as diversas formas de exercício da democracia, a questão da legalidade e da legitimidade do poder, os direitos dos cidadãos e suas diferentes formas de participação política. Cabe ressaltar a importância dos movimentos sociais no processo de construção da cidadania, em função do seu papel, cada vez expressivo, de interlocução com o poder público, desde o movimento operário até os chamados "novos movimentos sociais" (ecológico, pacifista, feminista etc.) (BRASIL, 1999, p. 324, grifos nossos).

Do mesmo modo, as orientações educacionais complementares aos Parâmetros Curriculares Nacionais $(\mathrm{PCN}+)$ indicou a cidadania como um de seus conceitos estruturadores para se trabalhar a Sociologia na sala de aula. De acordo com o documento, para elaboração desse conceito deve ser levado em conta mais especificamente alguns paradigmas teóricos e metodológicos da política em uma pesquisa que considere referenciais tais como as relações entre indivíduo e sociedade; as instituições sociais; a importância da participação política de indivíduos e grupos; os sistemas de poder e os regimes políticos; as formas do Estado; a democracia; os direitos dos cidadãos; os movimentos sociais, entre outros (BRASIL, 2000).

Ainda conforme a publicação, na articulação dos conceitos estruturadores com as competências específicas da Sociologia o conceito de cidadania deve compreender a participação politica do estudante enquanto cidadão que está construindo sua identidade social. Assim, foram sugeridos quatro eixos temáticos de organização da disciplina: a) Indivíduo e Sociedade; b) Cultura e Sociedade; c) Trabalho e Sociedade; e d) Política e Sociedade. As questões relativas ao conceito de Estado foram contempladas essencialmente no quarto eixo: 
Quadro 1 - Eixos

\begin{tabular}{|l|l|}
\hline \multicolumn{2}{|c|}{ Eixo Temático: Política e Sociedade } \\
\hline \multicolumn{1}{|c|}{ Temas } & \multicolumn{1}{c|}{ Subtemas } \\
\hline 1. Política e relações de poder & $\begin{array}{l}\text { • As relações de poder no cotidiano } \\
\bullet\end{array}$ \\
\hline A importância das ações políticas
\end{tabular}

Fonte: Orientações Educacionais Complementares aos PCN (2000)

Além dos PCN e dos PCN+, as Orientações Curriculares para o Ensino Médio (OCEM) e a crescente importância adquirida pelo Exame Nacional do Ensino Médio (ENEM) com sua matriz de referência em termos de habilidades e competências relacionadas à temática em questão só reforçaram o papel da política na formação básica do estudante.

As OCEM indicaram uma reestruturação dos PCN, demonstrando um novo patamar de definições de princípios para a reformulação curricular e, consequentemente, para o ensino de Sociologia. Nesse documento, foi elaborada uma crítica aos PCN-Sociologia e defendendo que as Ciências Sociais/Sociologia fossem compreendidas como disciplina do núcleo comum do currículo com um esforço de elaboração de propostas de conteúdos e de metodologias de ensino sintonizadas com os sentidos do ensino médio (MORAES, 2011).

Partindo-se de dois pressupostos - o estranhamento e a desnaturalização - as OCEMsociologia tem como princípio a vontade de saber mais e entender tudo, por não se conformar com alguma coisa ou com a situação em que se vive; não se acomodar e desenvolver uma visão crítica do senso comum. É perceber que a vida em sociedade é dinâmica, em constante transformação, ou 
seja, já vem carregado de significado social, político, econômico, cultural e histórico. Portanto, os conteúdos de caráter político da mesma forma se inserem em uma perspectiva crítica e de contextualização sócio histórica tendo como referência metodológica de ensino o uso de conceitos, temas e teorias, além da pesquisa.

Segundo Moraes (2011) discutindo as OCEM-sociologia, cada um dos três primeiros pressupostos - conceitos, temas e teorias - indica um caminho para o professor desenvolver o conteúdo programático sendo impossível trabalhar exclusivamente com um desses recortes sem que sejam feitas referências aos demais. Cada recorte, ao ser escolhido pelos professores para desenvolver determinada unidade do programa, atua como condutor central do trabalho docente. A pesquisa, por sua vez, é um procedimento que pode complementar o trabalho expositivo do professor, "sucedendo às aulas, exemplificando ou aprofundando empiricamente o que foi apresentado; ou pode, quando antecipa as aulas, provocar a curiosidade, o interesse, preparando o aluno para o que vai ser ensinado, sistematizado pelo professor" (p. 49).

Por fim, as Matrizes de Referência do ENEM compreenderam a aproximação dos conhecimentos de Geografia, História, Sociologia e Filosofia. Nesse sentido, ganha ênfase diversos temas intrínsecos ao ensino de política constante nos "Objetos de conhecimento associados às Matrizes de Referência”, anexo no mesmo documento. Como exemplo, na área de Ciências Humanas e suas Tecnologias, destacamos a linha Formas de organização social, movimentos sociais, pensamento político e ação do Estado:

- Cidadania e democracia na Antiguidade; Estado e direitos do cidadão a partir da Idade Moderna; democracia direta, indireta e representativa.

- Revoluções sociais e políticas na Europa Moderna.

- Formação territorial brasileira; as regiões brasileiras; políticas de reordenamento territorial.

- As lutas pela conquista da independência política das colônias da América.

- Grupos sociais em conflito no Brasil imperial e a construção da nação. 
- O desenvolvimento do pensamento liberal na sociedade capitalista e seus críticos nos séculos XIX e XX.

- Políticas de colonização, migração, imigração e emigração no Brasil nos séculos XIX e XX.

- A atuação dos grupos sociais e os grandes processos revolucionários do século XX: Revolução Bolchevique, Revolução Chinesa, Revolução Cubana.

- Geopolítica e conflitos entre os séculos XIX e XX: Imperialismo, a ocupação da Ásia e da África, as Guerras Mundiais e a Guerra Fria.

- Os sistemas totalitários na Europa do século XX: nazi-fascista, franquismo, salazarismo e stalinismo. Ditaduras políticas na América Latina: Estado Novo no Brasil e ditaduras na América.

- Conflitos político-culturais pós-Guerra Fria, reorganização política internacional e os organismos multilaterais nos séculos XX e XXI.

- A luta pela conquista de direitos pelos cidadãos: direitos civis, humanos, políticos e sociais. Direitos sociais nas constituições brasileiras. Políticas afirmativas.

Portanto, de forma direta ou indireta, o conceito de Estado perpassa todas as grandes questões políticas presentes nos objetos de conhecimento requeridos no ENEM, abrindo grandes possibilidades de atuação do professor da área de ciências humanas, em especial de sociologia. Vejamos agora, de forma breve, como essa temática é trabalhada pelos livros didáticos da disciplina.

\section{O CONCEITO DE ESTADO NOS LIVROS DIDÁTICOS DE SOCIOLOGIA}

A escolha do tema Estado se deu por conta da sua centralidade nas ciências sociais, como que sintetizando um dos conceitos chave do debate político na sociedade, além de ser uma teoria que muitas vezes é de difícil compreensão aos alunos. Partindo para a análise concreta, Araújo, Bridi e Motim (2013) abordam o tema no capítulo 8 intitulado "Cidadania, política e Estado". 
Segundo as autoras, o Estado é uma instituição social que permite - "ou, em alguns casos coíbe” - a participação ativa dos cidadãos nas grandes decisões da sociedade. Desse modo, a ciência política estuda o papel do Estado e as tensões entre os interesses coletivos e individuais nessa instituição social (p. 229).

Fazendo uso de Maquiavel, é feita uma reconstituição do exercício do poder político desde a Idade Moderna com a centralização política empreendida pelo Estado Absolutista. Sem citar uma obra específica, Max Weber também é utilizado na explicação da dominação que só seria legítima se fosse aceita pelos dominados. Em um box intitulado "Concepções de Estado e sociedade civil na Idade Moderna" é apresentado o conceito a partir de Hobbes, Locke e Rousseau relacionando - de forma original - o surgimento da sociedade civil com a burguesia, detalhe que escapa aos outros livros didáticos em estudo (ARAÚJO, BRIDI E MOTIM, 2013)

A visão marxista também está presente numa citação de Engels em A origem da família, da propriedade privada e do Estado na qual o poder estatal é caracterizado como um produto da sociedade e seu papel é amortecer os conflitos sociais e evitar o choque entre as classes, assegurando a reprodução do sistema social. No corpo do texto e no quadro "Interpretações sobre a natureza do Estado" são apresentadas de forma resumida outras concepções. Além de Marx, Engels e Weber, Gramsci, Althusser, Poulantzas e o sociólogo brasileiro Octavio Ianni completam o quadro-resumo (ARAÚJO, BRIDI E MOTIM, 2013).

$\mathrm{Na}$ obra Sociologia em Movimento (SILVA et al., 2013), os autores avançam cronologicamente e ao fazerem a caracterização do Estado moderno o associam a racionalização da gestão do poder (estrutura administrativa e burocrática) e esse fenômeno relacionado às revoluções liberais do século XVIII, destacadamente a Revolução Francesa. Nas seções seguintes são explicadas a Monarquia e a República como formas de organização do Estado moderno e Presidencialismo e Parlamentarismo como sistemas de governo. O uso de autores clássicos ou contemporâneos fica ausente nessas conceituações, assim como na explanação dos partidos políticos e sistemas eleitorais como formas de participação política.

Na seção "As relações de poder na sociedade contemporânea" os autores voltam a se referir à conceituação histórica de Estado dando-lhe cinco grandes características: povo, território, 
governo, finalidade e soberania, novamente descritos sem a utilização de um referencial teórico que as fundamente. Os autores serão utilizados apenas na caracterização dos diferentes Estados. Seguindo a ordem usual de conceituações desse tipo o Estado absolutista tem como principal referência Hobbes e principal característica a centralização e o despotismo do poder. No Estado liberal Locke e Adam Smith são os principais ideólogos do liberalismo político e econômico respectivamente e a ascensão da burguesia é sua principal especificidade.

A obra fez a opção teórica de não se preocupar em fazer diferença entre a Teoria Política (aquilo teorizado como ideal) e a Ciência Política (foco restrito às instituições formais) e, desse modo, acaba passando uma impressão negativa de certas teorias, em especial o socialismo confundido com o seu desvio autoritário, o Estado stalinista, que, entretanto, é apresentado como Estado socialista. Esse equívoco fica claro na caracterização seguinte dos Estados nazista e fascista tidos como regimes autônomos, sem serem conceituados como desvios autoritários do Estado liberal. O Estado de bem-estar social defendido por Keynes e colocado em prática no pós-Segunda Guerra e o Estado neoliberal a partir dos anos 1980 completam o quadro de definição do termo e utilização histórica.

Em Sociologia hoje (MACHADO, AMORIM E BARROS, 2017), é apresentado o conceito de Estado recorrendo a praticamente um único autor: Max Weber. O monopólio da violência legítima é esmiuçado pelos autores inclusive com uma citação direta do próprio autor. Outros dois autores que ainda são utilizados de forma rápida na definição de Estado são Charles Tilly, um autor contemporâneo que poderia ter sido melhor aproveitado ao invés de apenas para dizer que "quando se formaram, os Estados modernos não eram muito diferentes de quadrilhas criminosas que, para não agredir o povo, cobravam dele" (p. 255). O outro é Gramsci, usado na caracterização por conta do conceito de hegemonia.

Após um box com o perfil de Maquiavel, a temática estatal é finalizada com a seção "Os contratualistas: o que o Estado pode fazer?” no qual é explicado novamente a partir das concepções de Hobbes, Locke e Rousseau, inclusive com um quadro resumo sobre os três autores dividido em três colunas: Como seria a vida sem o Estado?; Por que se formaria o Estado? e O que as pessoas poderiam esperar do Estado? Chama atenção nessa obra como apenas a teoria política liberal é 
levada em conta, excluindo-se outras visões, desde a concepção conservadora positivista/ funcionalista até as perspectivas socialistas, tanto reformistas como revolucionárias. Inclusive, Gramsci quando é rapidamente citado parece ser um liberal.

O livro Sociologia para jovens do século XXI (OLIVEIRA; COSTA, 2016), faz a discussão a partir do capítulo "'O Estado sou eu'. Estado e democracia” no qual faz alusão à famosa frase atribuída ao rei Luís XIV para fazer referência de como se modificou o Estado nos dias atuais. Caracterizado por uma ordem jurídica e funções impessoais tais como elaborar leis, administrar os serviços públicos e julgar a aplicação das leis, papel dos três poderes do Estado, o Legislativo, Executivo e Judiciário, respectivamente.

Assim como todas as obras anteriores analisadas, essa também acertadamente fará referência a Weber na sua conceituação. O que traz de original é ser o único dos cinco livros analisados que também se utiliza de Durkheim para expor como o Estado exerce uma coerção sobre os indivíduos, além de Marx:

Segundo esta visão, o Estado teria surgido, na História da humanidade, como resultado do conflito existente entre classes sociais antagônicas. Assim, o Estado teria se tornado uma necessidade concreta das classes economicamente dominantes, objetivando novos meios de dominação política, de repressão e de exploração das classes oprimidas (p. 200).

Desse modo, os três autores clássicos da sociologia são chamados a dar a sua contribuição ao fenômeno estatal que no mesmo capítulo ainda trabalha a questão da democracia e dos partidos políticos brasileiros.

Por fim, Tempos modernos, tempos de sociologia (BOMENY et al., 2016) é a única obra que não faz uma conceituação clara de Estado, preocupando-se mais em identificar os termos política e poder. Ao falar do fenômeno político, utilizando Maquiavel, faz apenas uma referência indireta ao Estado: “A finalidade da política seria a manutenção do Estado. Tudo, portanto, que dissesse respeito ao funcionamento do Estado - ato de governar, de obedecer, de administrar conflitos, de se representar - interessava ao funcionamento da política” (p. 55).

Também de forma indireta o box "Teoria contratualistas ou teorias do contrato social" procura debater a origem da ordem social e da política. Colocando o contratualismo como uma 
corrente filosófica surgida na Antiguidade e que "atravessou o Período Medieval", foi na modernidade que pôde contribuir para o desenvolvimento da ciência política. Segundo as autoras, com a base teórica fornecida pelos contratualistas, o estado de natureza pôde desaparecer e "surge da sociedade civil (civitas, 'Estado', 'organização política')”. (p. 56).

\section{CONSIDERAÇÕES FINAIS: AS POSSIBILIDADES DE TRABALHO CRÍTICO COM O CONCEITO DE ESTADO}

O conceito de Estado é central nas ciências humanas em geral e nas ciências sociais em particular. Como procuramos demonstrar aqui, isso pode ser visto tanto na ênfase dada à temática nos documentos oficiais como nos livros didáticos. Infelizmente, nem todos os livros oferecem as diferentes visões sociológicas e políticas possíveis acerca do poder estatal (conservadora, liberal e socialista) advinda dos clássicos Durkheim, Weber e Marx, respectivamente, ou autores contemporâneos críticos como Gramsci e Bourdieu. Mesmo o debate mais atual das concepções Social-Democrata e Neoliberal em disputa é pouco explorado. A maioria apresenta apenas a visão vitoriosa de Estado, ou seja, a perspectiva liberal contratualista e weberiana propagada no senso comum, nas universidades e instituições políticas e reproduzida nos meios de comunicação como a única alternativa possível.

No entanto, o professor ao ter consciência dessas limitações pode fazer a mediação necessária para garantir a ampliação dessa visão restrita. $\mathrm{Na}$ medida do possível, as atividades pedagógicas devem ser realizadas em torno das relações entre política e sociedade e devem ter como finalidade ampliar a concepção que o aluno tem de política. Ao perceber a política como uma rede de interesses e de acordos estabelecidos pelas pessoas em um processo de tomadas de decisões que gira em torno de valores sociais e de relações de poder, o estudante passa a entender e identificar a presença da política no agir cotidiano de indivíduos, grupos e instituições.

Resgatando o que foi preconizado pelos PCN's, o estudo do Estado deve produzir uma síntese que contemple as diversas teorias sobre sua origem e finalidade. Determinadas formas históricas de Estado, o Absolutista, o Liberal, o Democrático, o Socialista, o Welfare-State (o do 
Bem-Estar) e o Neoliberal, devem ser abordadas e comparadas, em suas características, com o Estado Brasileiro atual. Já o estudo do Estado brasileiro e dos regimes políticos que se sucederam no país possibilita a contextualização necessária à apropriação dos conceitos da ciência política, assim como escolher e investigar um determinado movimento social pode permitir a realização de inúmeras atividades pedagógicas.

As questões que podem ser feitas a partir deste tema são relativas às alterações nas estruturas e instituições sociais. "Por que as sociedades se transformam? Qual o papel dos indivíduos, dos grupos e das classes sociais nas mudanças? Quais são as estruturas de poder dentro da sociedade? Como é possível agir para transformar? Por que cidadania e democracia são valores tão importantes?". Ao compreender melhor a dinâmica da sociedade em que vive e as alternativas que existem, esse estudante poderá perceber-se como elemento ativo, dotado de força política e capacidade de transformar, ou mesmo, viabilizar, através do exercício pleno de sua cidadania, mudanças que apontem para um modelo de sociedade mais justo e solidário.

\section{REFERÊNCIAS}

AÇÃO EDUCATIVA (Org.). A ideologia do movimento Escola Sem Partido: 20 autores desmontam o discurso. São Paulo: Ação Educativa, 2016.

ARAÚJO, S. M.; BRIDI, M. A.; MOTIM, B. L. Sociologia: ensino médio. São Paulo: Scipione, 2013.

BRAGA, R. Atravessando o abismo: uma sociologia pública para o ensino médio. In: BRAGA, R.; BURAWOY, M. (Org.). Por uma sociologia pública. São Paulo: Alameda, 2009.

BRASIL. Parâmetros curriculares nacionais: ensino médio. Brasília: MEC/SEMTEC, 1999.

- PCN ensino médio: orientações educacionais complementares aos Parâmetros Curriculares Nacionais. Brasília: MEC/SEMTEC, 2000.

BOMENY, H. et al. (Coord.). Tempos modernos, tempos de sociologia: ensino médio São Paulo: Editora do Brasil, 2013.

MACHADO, I. J. R. et al. Sociologia hoje: ensino médio. São Paulo: Ática, 2013. 
MEUCCI, S. Notas sobre o pensamento social brasileiro nos livros didáticos de sociologia. In: . Revista Brasileira de Sociologia, vol. 02, nº 03, jan.-jun. 2014.

MORAES, A. C. Metodologia de ensino de Ciências Sociais: relendo as OCEM-Sociologia. In: (Coord.). Sociologia: ensino médio. Brasília: Ministério da Educação, Secretaria de Educação Básica, 2011 (Coleção Explorando o Ensino; v. 15).

OLIVEIRA, L. F.; COSTA, R. C. R. Sociologia para jovens do século XXI. Rio de Janeiro: Imperial Novo Milênio, 2013.

REVISTA VEJA. Bolsonaro defende gravação de professores por alunos em sala de aula. Disponível em: https://veja.abril.com.br/politica/bolsonaro-defende-gravacao-de-professores-poralunos-em-sala-de-aula/. Acesso em: 29 de abril de 2019.

SILVA, A. et al. Sociologia em movimento. São Paulo: Moderna, 2013. 